\title{
Dissociable Memory Traces within the Macaque Medial Temporal Lobe Predict Subsequent Recognition Performance
}

\author{
Kentaro Miyamoto, Yusuke Adachi, ${ }^{\star}$ Takahiro Osada, ${ }^{\star}$ Takamitsu Watanabe, Hiroko M. Kimura, Rieko Setsuie, \\ and Yasushi Miyashita \\ Department of Physiology, The University of Tokyo School of Medicine, 7-3-1 Hongo, Bunkyo-ku, Tokyo 113-0033, Japan
}

Functional magnetic resonance imaging (fMRI) studies have revealed that activity in the medial temporal lobe (MTL) predicts subsequent memory performance in humans. Because of limited knowledge on cytoarchitecture and axonal projections of the human MTL, precise localization and characterization of the areas that can predict subsequent memory performance are benefited by the use of nonhuman primates in which integrated approach of the MRI- and cytoarchiture-based boundary delineation is available. However, neural correlates of this subsequent memory effect have not yet been identified in monkeys. Here, we used fMRI to examine activity in the MTL during memory encoding of events that monkeys later remembered or forgot. Application of both multivoxel pattern analysis and conventional univariate analysis to high-resolution fMRI data allowed us to identify memory traces within the caudal entorhinal cortex (cERC) and perirhinal cortex (PRC), as well as within the hippocampus proper. Furthermore, activity in the cERC and the hippocampus, which are directly connected, was responsible for encoding the initial items of sequentially presented pictures, which may reflect recollection-like recognition, whereas activity in the PRC was not. These results suggest that two qualitatively distinct encoding processes work in the monkey MTL and that recollection-based memory is formed by the interplay of the hippocampus with the cERC, a focal cortical area anatomically closer to the hippocampus and hierarchically higher than previously believed. These findings will advance the understanding of common memory system between humans and monkeys and accelerate fine electrophysiological characterization of these dissociable memory traces in the monkey MTL.

\section{Introduction}

For many decades, the medial temporal lobe (MTL) has been investigated as a critical locus of memory processes (Squire et al., 2004). A series of human studies using functional magnetic resonance imaging (fMRI) have found that fMRI signals recorded from the MTL during encoding of subsequently recognized stimuli (later Hit) significantly differed from those recorded during encoding of subsequently forgotten stimuli (later Miss). This is termed the "subsequent memory effect" and has been reported to be localized in the hippocampus and in the perirhinal and parahippocampal cortices within the "parahippocampal region" (Wagner et al., 1998; Wais, 2008). These memory traces have been differentiated according to their cognitive functions, including recollection/familiarity (remember/know) and source/

Received Sept. 20, 2013; revised Dec. 8, 2013; accepted Jan. 2, 2014.

Author contributions: K.M. and Y.M. designed research; K.M., Y.A., T.O., and H.M.K. performed research;Y.A. and

T.0. contributed unpublished reagents/analytic tools; K.M., Y.A., T.O., T.W., and Y.M. analyzed data; K.M., Y.A., T.O., T.W., R.S., and Y.M. wrote the paper.

This work was supported in part by MEXT/JSPS KAKENHI Grants 19002010 and 24220008 to Y.M., CREST, Japan Science and Technology Agency to Y.M., Takeda Science Foundation to Y.M., and Grant 234682 from the Japan Society for the Promotion of Science Research Fellowships for Young Scientists to K.M. One Japanese monkey used in this research was provided by NBRP "Japanese Monkeys" through the National BioResource Project of the MEXT. We thank Tomomi Watanabe for technical assistance and Seiki Konishi for helpful comments on the manuscript.

The authors declare no competing financial interests.

*Y.A. and T.O. contributed equally to this work.

Correspondence should be addressed to Dr. Yasushi Miyashita, Department of Physiology, University of Tokyo School of Medicine, 7-3-1 Hongo, Bunkyo-ku, Tokyo 113-0033, Japan. E-mail:yasushi_miyashita@m.u-tokyo.ac.jp.

DOl:10.1523/JNEUROSCI.4048-13.2014

Copyright $\odot 2014$ the authors $\quad 0270-6474 / 14 / 341988-10 \$ 15.00 / 0$ item recognition (Strange et al., 2002; Ranganath et al., 2004; Davachi, 2006). However, it remains difficult to precisely localize the loci that underlie the subsequent memory effect within the human parahippocampal region because information on the cytoarchitecture and axonal projections in these cortices is limited in humans, and MRI-based boundary delineation within these regions has not yet been established (see also Anatomy and nomenclature of "parahippocampal region" in Materials and Methods, below) (Insausti et al., 1998).

Studies of nonhuman primate models are beneficial to address this difficulty, as a wealth of information is available on the electrophysiology, histology, and lesion studies (Brown and Aggleton, 2001; Miyashita, 2004). Especially, the anatomical reference frame in the parahippocampal region is established in the macaque monkeys, which would be helpful for fine localization of memory traces. The macaque perirhinal cortex (PRC) is cytoarchitectonically divided into area 36 and area 35 according to the presence or absence of layer IV; and based on cytoarchitectonic criteria, the macaque entorhinal cortex is further subdivided into six subdivisions, where predominant cortical inputs are differentiated: afferents from the PRC mainly project anteriorly and those from the parahippocampal cortex (PHC) mainly project posteriorly (Suzuki and Amaral, 1994b, 2003b). However, the distribution of neural correlates of subsequent memory effects has not been studied in monkeys.

Here, we conducted fMRI experiments using awake macaque monkeys (Logothetis et al., 1999; Nakahara et al., 2002; Tsao et al., 2003; Pinsk et al., 2005; Durand et al., 2007; Maier et al., 2008; 
Ford et al., 2009; Kagan et al., 2010; Wang et al., 2013) and acquired fine, high-resolution functional images that enabled precise localization of subsequent memory effects. Our highresolution mapping allowed us to precisely localize a memory trace in area 36 within PRC, which is consistent with humans. However, contrary to predictions from human studies, other memory trace reflecting recollection-like recognition was localized in the caudal entorhinal cortex (cERC) rather than in the PHC. These locations were identified by both multivoxel pattern analysis (Haynes and Rees, 2005; Kamitani and Tong, 2005) (especially, the "searchlight" method) (Kriegeskorte et al., 2006) and conventional univariate analysis. These findings, providing precise localization of memory traces in monkeys, bridge the gap between imaging studies on humans and anatomical studies on nonhuman primates and can accelerate fine electrophysiological characterization of memory traces in the monkey MTL.

\section{Materials and Methods}

Subjects. All the experimental protocols were in full compliance with the regulations of the University of Tokyo School of Medicine and with the National Institutes of Health Guidelines for the Care and Use of Laboratory Animals. Two adult monkeys (Macaca fuscata; Monkey A: female, 6 $\mathrm{kg}$; Monkey V: male, $8 \mathrm{~kg}$ ) participated in the experiment. fMRI experiments were conducted as described previously (Nakahara et al., 2002; Koyama et al., 2004; Miyamoto et al., 2013). Online behavioral control and reward delivery were implemented in the presentation platform as described previously (Miyamoto et al., 2013).

Behavioral tasks. The procedure for the fMRI-modified serial probe recognition task (see Fig. $1 A$ ) has been described in detail previously (Miyamoto et al., 2013). In brief, each trial began with the presentation of a fixation point after the monkey pulled the joystick. The four list items then appeared sequentially. Each item was presented at the center of the monitor for $1 \mathrm{~s}$, followed by a $1 \mathrm{~s}$ interstimulus interval. The items were selected from a 1000 picture pool in a pseudo-random order. Typically, each picture was presented in only one trial (two trials at most) during each session. The last cue item was followed by a delay period that varied between 7 and $10 \mathrm{~s}$ across trials. Finally, the monkey was presented with one test item at the center of the monitor and two symbols, a triangle and a cross, on the left and right sides of the image. The assignment of symbols to the left or right side of the screen during each trial was random. In half of the trials, the test item presented in the choice period was the same as one of the cue items; in the other half, the item was not presented as a cue item. Monkeys responded by moving the joystick in direction of the "seen" symbol (a triangle for Monkey A and a cross for Monkey V) if the test item was from the cue item list or by moving the joystick in direction of the "unseen" symbol (a cross for Monkey A and a triangle for Monkey $\mathrm{V}$ ) if the test item was not from the cue list. The monkey received juice drops accompanied by a distinctive secondary visual reinforcement. Incorrect choices resulted in termination of the trial without reward. Trials were separated by a $4 \mathrm{~s}$ intertrial interval, during which the screen was black. If any limbs moved during the trials, the optic sensors detected the movement and the trial was aborted immediately. The monkeys also performed a single-probe recognition task (number of cue items $=1$ ). The task procedure was the same as described above, but a single item was used for the cue.

Data acquisition. Functional images were acquired using a 4.7-T MRI scanner (Biospec 47/40, Bruker) with $100 \mathrm{mT} / \mathrm{m}$ actively shielded gradient coils and a transceiver saddle RF coil (Takashima) (Adachi et al., 2012; Matsui et al., 2012; Miyamoto et al., 2013). During each session, functional data were acquired using a gradient-echo echo-planar imaging sequence $\left(1\right.$ shot, $\mathrm{TR}=2.5 \mathrm{~s}, \mathrm{TE}=20 \mathrm{~ms}, 1.25 \times 1.5 \mathrm{~mm}^{2}$ in-plane resolution, $64 \times 96$ matrix, slice thickness $=1.5 \mathrm{~mm}$ with interslice gap $=0.25 \mathrm{~mm}, 27$ horizontal slices covering the whole brain).

Multivoxel classification analysis. To localize the regions that were predictive of subsequent memory performance, the data from the singleprobe recognition task were preprocessed using SPM5 software (http://www.fil.ion.ucl.ac.uk/spm). Functional images were realigned,
Table 1. Coordinates of voxels with the highest classification accuracy in the hippocampus (HC), PRC, and CERC during the single-probe recognition task

\begin{tabular}{rrrrr}
\hline & \multicolumn{1}{c}{$x$} & $y$ & Accuracy (\%) \\
\hline $\begin{array}{c}\text { Monkey A } \\
\text { PRC }\end{array}$ & & & & \\
L & -11 & 4 & -17 & 85.5 \\
R & 11 & 3 & -18 & 86.2 \\
CERC & & & & \\
L & -7 & -7 & -15 & 90.0 \\
R & 8 & -7 & -15 & 89.4 \\
HC & & & & \\
L & -11 & -17 & 2 & 95.1 \\
R & 10 & -8 & -11 & 97.7 \\
Monkey V & & & & \\
PRC & & & -19 & 61.8 \\
L & -11 & 3 & -19 & 69.0 \\
R & 11 & 3 & -16 & 66.4 \\
CERC & & & -14 & 62.8 \\
L & -6 & -2 & -12 & 69.8 \\
R & 6 & -5 & -13 & 64.6 \\
HC & & & & \\
L & -14 & -5 & -4 & \\
R & 14 & & &
\end{tabular}

$L$, left; R, right.

corrected for slice timing, and spatially normalized to the template image by interpolation to a $1 \times 1 \times 1 \mathrm{~mm}^{3}$ space, but without any spatial smoothing. The template image was constructed from the highresolution echo-planar imaging of each monkey by coregistering it to each monkey's anatomical template MDEFT image arranged in bicommissural space in which the origin was placed at the anterior commissure (Nakahara et al., 2002; Koyama et al., 2004; Miyamoto et al., 2013).

Subsequent memory prediction was performed using a multivariate searchlight strategy, which examines the information in the local spatial patterns surrounding each voxel within the search space limited to the MTL (Haynes and Rees, 2005; Kamitani and Tong, 2005; Kay et al., 2008; Mitchell et al., 2008; Hassabis et al., 2009; Johnson et al., 2009; Watanabe et al., 2011). Before the analysis, time series during the single-probe recognition and serial probe recognition tasks were separately estimated for "later Hit" and "later Miss" trials in each session using canonical hemodynamic response functions. This multivoxel classification analysis was achieved by splitting the subsequent memory prediction data into a training set and a test set. The training set was then used to train a linear support vector machine classifier using the LIBSVM (http://www.csie. ntu.edu.tw/ $\sim$ cjlin/libsvm/) implementation. A standard $k$-fold crossvalidation testing regimen was used where $k$ was equal to the number of estimated time series. The data from each time series were set aside and used, in turn, as the test data; the remaining data were used as the training data. This method generated $k$ sets for the linear support vector machine training and test sets that were used to derive an overall classification accuracy from the proportion of correct classification guesses across all $k$-folds of the cross-validation. This procedure was repeated for each searchlight sphere (radius $=2 \mathrm{~mm}$ ), thereby generating a percentage accuracy value for every single voxel within the search space. Data from 24 sessions (3262 trials) for Monkey A and 26 sessions (1337 trials) for Monkey V were analyzed. From the map derived for each monkey, the peaks showing the highest classification accuracy values (listed in Table 1) were extracted and labeled by referring to the atlas of Paxinos et al. (2008) and the nomenclature of the "parahippocampal region" as described below. We determined interareal borders by aligning the anatomical regions defined by Caret software (version 5.61; http://brainvis. wustl.edu/wiki/index.php/Caret:About) to each monkey's template images (see Fig. 2B). For the serial-probe recognition task data, classification performance was calculated separately for initial items and middle items using the $k$-fold cross-validation. Data from 15 sessions (2108 trials) for Monkey A and 11 sessions (558 trials) for Monkey V were analyzed. Two-way ANOVA was performed on the classification accuracy data after arcsine transformation with the factors of position (initial, 
Table 2. Brain regions activated in "later Hit" > "later Miss" contrasts in the MTL during the single-probe recognition $\operatorname{task}^{a}$

\begin{tabular}{lrrlll}
\hline & \multicolumn{1}{c}{$x$} & $y$ & $z$ & $T$ & Area \\
\hline $\mathrm{L}$ & -8 & 2 & -17 & 4.18 & PRC \\
$\mathrm{R}$ & 10 & 2 & -16 & 3.42 & PRC \\
$\mathrm{L}$ & -4 & -6 & -15 & 4.86 & CERC \\
$\mathrm{R}$ & 11 & -10 & -15 & 3.61 & CERC \\
\hline
\end{tabular}

$\bar{a}$ Univariate analysis. Significant peaks with a voxel level of $p<0.05$ (corrected by false discovery rate) within the MTL. L, left; $R$, right.

middle) and area (2 $\mathrm{mm}$ radius sphere around bilateral peaks [listed in Table 1] within the hippocampus, cERC, and PRC derived from the multivoxel classification analysis for the single-probe recognition task). Classification accuracies calculated in each hemisphere were averaged.

Univariate analysis. The encoding success regions were identified by performing voxelwise general linear model (GLM) analyses in SPM5. These analyses included the following predictors: $(1-4)$ the choice onsets in Hit, Correct Rejection (CR), Miss, and False Alarm (FA) trials; (5-9) the cue onsets in Hit, CR, Miss, FA, and other (aborted) trials; and (10) the timing of other types of errors. These events were modeled as $\delta$ functions, convolved with the canonical hemodynamic response function and its temporal and dispersion derivatives. The six parameters of head motion derived from realignment were also included in the model as covariates of no interest. Data were high-pass filtered using a cutoff of $32 \mathrm{~s}$.

Group analysis of the fMRI data derived from the two monkeys, preprocessed as above and spatially smoothed with a Gaussian kernel ( $3 \mathrm{~mm}$ full-width at half-maximum), was conducted using a fixed-effect model. Functional images from both monkeys were spatially normalized to the template image derived from Monkey A. Encoding success regions were identified according to the group analysis map (see Fig. $3 A$ ) for the comparison of BOLD signals between the "later Hit" (cue onsets in Hit) and "later Miss" (cue onsets in Miss) trials (Wagner et al., 1998). The coordinates of the activation peaks at which the $t$ value was significant at $q<$ 0.05 with false discovery rate [FDR] correction within the MTL (Genovese et al., 2002) are listed in Table 2 . We additionally present the BOLD time courses for later Hit and later Miss trials to demonstrate the strength of the activations. Time course data were extracted using the MarsBaR ROI toolbox for SPM (http://marsbar.sourceforge.net/).

For the serial probe recognition task, voxelwise GLM analyses were also conducted and significant activation peaks were searched within each region of interest determined in the GLM analysis for the singleprobe recognition task (see Fig. 3A). The regions of interest for each pair of bilateral activation peaks within MTL were defined as the significantly activated voxels within a $2 \mathrm{~mm}$ radius ( $q<0.05$ with FDR correction). Hit and Miss trials were further classified into three categories according to the position of the test item in the cue sequence: Hit [Initial, Middle, Last] and Miss [Initial, Middle, Last]. To examine the effect of test item position in the cue sequence on the encoding success activity in each homotopic pair of regions of interest listed in Table 2 (the PRC and cERC), BOLD signals were separately compared between the "later Hit" and "later Miss" trials for the initial and middle items in group analysis ( $\alpha=0.05$, family-wise error [FWE]-corrected within each pair of regions of interest). Two-way ANOVA was performed on the activation values of each monkey with the factors of position (initial, middle) and area ( $3 \mathrm{~mm}$ radius sphere around bilateral peaks within cERC and PRC where significant activation $[q<0.05$, FDR-corrected] was observed during the singleprobe recognition task).

In addition, we estimated the correlation between accuracy and BOLD signal in the two regions for the initial and middle items. Atypical sessions, in which task accuracy differed from the average by $>20 \%$, were omitted. Accuracy and brain activity varied across sessions for each monkey were Z-transformed before the correlation coefficient was calculated.

Anatomy and nomenclature of the "parahippocampal region." In the present study, we focused on the "parahippocampal region," along with the hippocampus in the MTL. The parahippocampal region, as is often referred to in previous studies, comprises the perirhinal, parahippocampal, and entorhinal cortices (Burwell, 2000; Van Hoesen et al., 2000). In monkeys, these areas are situated on the anterior-ventral portion of the
MTL and surround the amygdala anteriorly and the hippocampus posteriorly (Van Hoesen et al., 2000). Demarcation of the region in the present study was mostly based on Suzuki and Amaral (Suzuki and Amaral, 1994a, b, 2003a, b).

The monkey PRC is situated lateral to the fundus of the rhinal sulcus and extends from the posterior border of the rhinal sulcus on the ventral surface of the temporal lobe to the anterior and the dorsal portion of the rhinal sulcus on the temporal pole. The perhinal cortex has been further subdivided into area 35, which forms a long and narrow strip of cortex in the fundus and lateral bank of the rhinal sulcus, and a larger, more laterally situated area 36 (Suzuki and Amaral, 1994a, b, 2003b, a). However, there exist controversies over the nomenclature and border of the monkey PRC. First, regarding the nomenclature, some investigators define only the area 35 as the PRC and distinguish it from area 36, which is labeled as the ectorhinal cortex (Ding and Van Hoesen, 2010; Augustinack et al., 2013). Others have grouped perirhinal (area 35) and entorhinal (area 28) together and referred to it as the rhinal cortex (Murray and Mishkin, 1986; Meunier et al., 1996). Here, we referred to both areas 35 and 36 as the PRC and distinguished the PRC from the entorhinal cortex (Suzuki and Amaral, 1994a, b, 2003a, b). Second, regarding the border, some researchers concern whether the dorsal or ventral temporal pole adjacent to the rhinal sulcus should also be considered part of the PRC. Here, we included the ventral temporal pole but excluded the dorsal temporal pole, in terms of anatomical connections and cytoarchitectonic features (Suzuki and Amaral, 1994a; Kondo et al., 2003, 2005; Saleem et al., 2008).

The entorhinal and parahippocampal cortices in monkeys are located on the parahippocampal gyrus, which is separated from the temporal polar cortex and the inferior temporal area by the rhinal sulcus anteriorly and the occipitotemporal sulcus posteriorly. The entorhinal cortex locates anteriorly in the most sizable part of the parahippocampal gyrus. The entorhinal cortex forming area 28 has further been subdivided into six subdivisions based mainly on cytoarchitectonic criteria (Amaral et al., 1987). In the present study, we referred the caudal division (area EC) and the caudal limiting division (area ECL) out of the six subdivisions as the cERC. In general, the monkey entorhinal cortex enjoys the least controversy over the location of its borders, compared with the perirhinal and parahippocampal cortices. The monkey PHC locates posteriorly on the parahippocampal gyrus and situated just caudal to both the entorhinal and PRC. The cortical area is made up of areas TH and TF defined by cytoarchitectonic features, although a controversy exists over the lateral border of the area TF (Suzuki and Amaral, 1994b, 2003b; Blatt et al., 2003; Kondo et al., 2005; Saleem et al., 2008).

In humans, much of the parahippocampal region, including the entorhinal, perirhinal, and parahippocampal cortices, locates on the parahippocampal gyrus (Van Hoesen et al., 2000; Ding and Van Hoesen, 2010). The parahippocampal gyrus is separated from the temporal neocortex laterally by the often variant collateral and rhinal sulci in humans (for a large individual variance in configuration of the human collateral and rhinal sulci, see Van Hoesen et al., 2000). If the rhinal sulcus is present, the human PRC is located in its fundus and lateral bank, as is the case for nonhuman primates, and in the perirhinal gyrus between the rhinal sulcus and collateral sulcus. Even if the rhinal sulcus is absent, the PRC aligns itself with the collateral sulcus and continues posteriorly. MRIbased boundary delineation between the entorhinal and perirhinal cortices in the human MTL has been proposed (Insausti et al., 1998). However, the areal demarcation within either the entorhinal or the PRC for humans has not been examined in the same way as that for monkeys. On the other hand, although the human entorhinal cortex (area 28) and PHC (areas TF and TH) are located in the parahippocampal gyrus, posteriorly and ventrally to the primary olfactory cortex, MRI-based boundary delineation between these cortices has not yet been established in humans.

\section{Results}

\section{Behavioral results}

We conducted fMRI studies on two macaque monkeys that were performing a single-probe recognition task with one cue item and a serial probe recognition task with four cue items in each list 
A

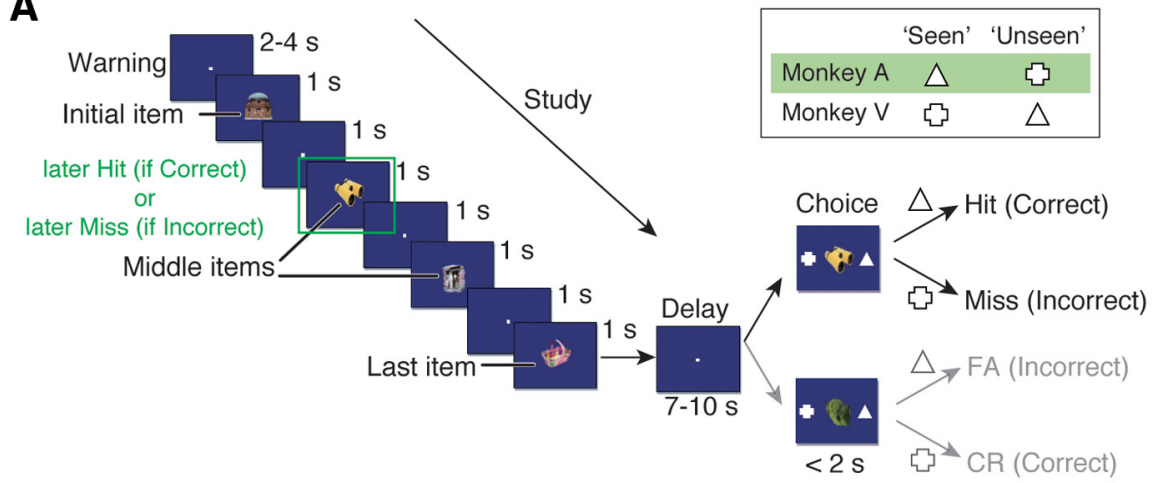

B

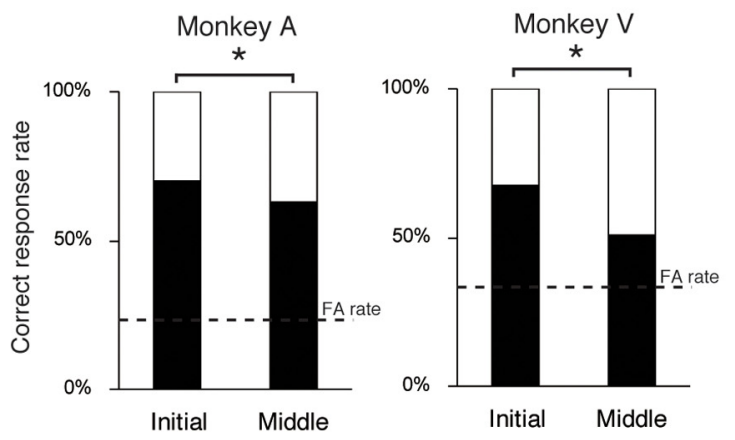

Figure 1. Serial probe recognition task and behavioral performance of monkeys. $A$, Trial structure for the serial probe recognition task. The monkey pulled the joystick to initiate each trial (Warning). Four cue items (i.e., objects) to study were then presented sequentially (Initial, Middle, and Last items). After a 7-10 s delay (Delay), two choice symbols were presented along with a test item (Choice). The symbols, a triangle and a cross, were differentially defined as "seen" and "unseen" for each monkey (see inset table). Monkeys were required to select the "seen" (or "unseen") symbol if the test item was (or was not) included in the studied list of items. The classification of the Hit and CR trials for Monkey A is shown here. $\boldsymbol{B}$, The percentage of correct (filled bars) and incorrect (open bars) responses made by each monkey when the test item was the first object presented in the list (Initial) or the second or third items presented in the list (Middle) in the serial probe recognition task during the scanning sessions. ${ }^{*} p<0.05$ ( $\chi^{2}$ test).

which every cluster in the MTL contained the information about the classification accuracy of the subsequent recognition performance, that is, whether the monkey remembered (later Hit) or forgot (later Miss) (Fig. 2A). In the parahippocampal region, the bilateral significant peaks of classification accuracy common to both monkeys were located within area 36 of the PRC and within the cERC (Fig. $2 A, B$ ). The pattern of activity in these two cortices and the hippocampus predicted subsequent recognition performance with significantly high accuracy (PRC, Monkey A: $p=6 \times 10^{-9}$, Monkey V: $p=0.003$; cERC, Monkey A: $p=6 \times 10^{-9}$, Monkey V: $p=0.003$; hippocampus, Monkey A: $p=4 \times 10^{-12}$, Monkey V: $p=0.01$; Table 1).

\section{Prediction of subsequent memory performance by the hippocampus, cERC, and PRC activity differentially depends on the list position of the cue item}

Next, we examined whether the dependency of decoding accuracy on the position of the cue items in the serial probe recognition task differed across the hippocampus, PRC, and cERC (Fig. $3 A$ ). Two-way ANOVA (two positions [initial, middle] $\times$ three areas) identified a significant interaction between position and area $\left(F_{(2,2)}=41.7, p=0.02\right)$, although neither position $\left(F_{(1,1)}=57.4, p=0.08\right)$

(Fig. 1A) (Miyamoto et al., 2013). During these tasks, the monkeys were required to judge whether or not the item in the choice period was seen during the preceding cue period. In the serial probe recognition task, consistent with previous studies in humans and monkeys (Wright et al., 1985), U-shaped serial position curves representing the percentage of correct responses were obtained in both monkeys, indicating the presence of both primacy and recency effects (Miyamoto et al., 2013). In the present study, we focused on the encoding processes of initial or middle cue items, which are considered to be dependent on the longterm memory process (Wright et al., 1985; Miyamoto et al., 2013). Retrieval of the last items on the list is related to the recency effect and is considered to reflect working memory process rather than long-term memory process. For this reason, we excluded the last item on the list from the analyses. The corrected recognition rate (defined as "Hit rate" - "FA rate") for each position of the cue item (initial, middle) was significantly positive for both monkeys ( $\chi^{2}$ test; $p<0.05$, for each item for both monkeys). The accuracy was significantly higher for the initial list position than for the middle list positions ( $\chi^{2}$ test; Monkey A: $p=$ 0.04; Monkey V: $p<0.001$; Fig. $1 B)$.

\section{Decoding memory traces in the monkey MTL using multivariate classification}

To localize the neural correlates of the subsequent memory effect in the monkey MTL, we applied the searchlight method, a multivariate decoding technique that is based on a linear support vector machine, to the $\mathrm{AMRI}$ signals recorded from the MTL during cue periods in the single-probe recognition task. We generated an accuracy map, in nor area $\left(F_{(1,2)}=0.15, p>0.5\right)$ showed a significant main effect. The three areas were then dissociated to determine their contribution to encoding items in different positions in the cue list. Tests for simple main effects revealed that the decoding accuracy of the $\operatorname{cERC}\left(F_{(1,3)}=74.4, p=0.003\right)$ and the bilateral hippocampi $\left(F_{(1,3)}=16.1, p=0.02\right)$ was significantly higher for initial items than for middle items, whereas the accuracy of the PRC was significantly higher for middle items than for initial items $\left(F_{(1,3)}=38.3, p=0.008\right)$. The accuracy maps in the serial probe recognition task, which were generated separately for encoding of the initial or middle items, jointly overlapped with the accuracy maps from the single-probe recognition task (Fig. 3B). These results indicate that the PRC and the cERC along with the hippocampus were engaged in two distinct encoding processes that worked differentially depending on the position of the item in the memorized list.

\section{Neural correlates of subsequent memory effects in the monkey MTL identified by univariate analysis}

We next examined whether the results of the multivoxel pattern analysis were consistent with those of conventional univariate analysis. To identify the regions that predicted subsequent recognition performance, we compared activity levels during cue periods in which monkeys remembered (later Hit) the item presented during the choice period to activity levels during cue periods in which monkeys forgot (later Miss) the item presented during the choice period in the single-probe recognition task (Fig. 4A; later Hit vs later Miss). In the MTL, significant peaks were detected bilaterally in the PRC $(p<0.05$, FDR-corrected within the MTL) 
A

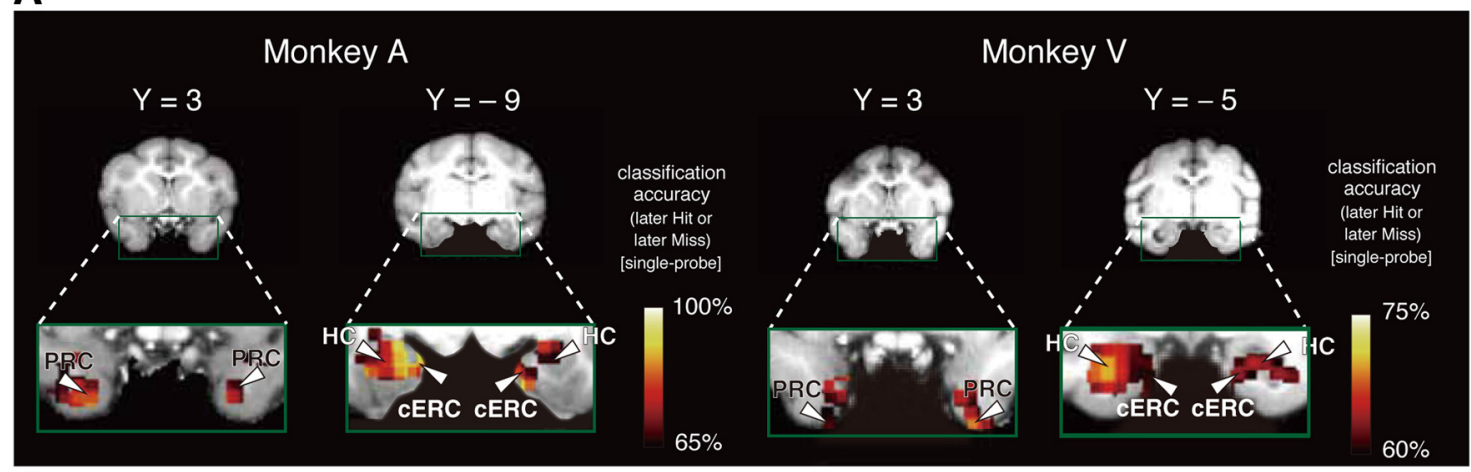

B

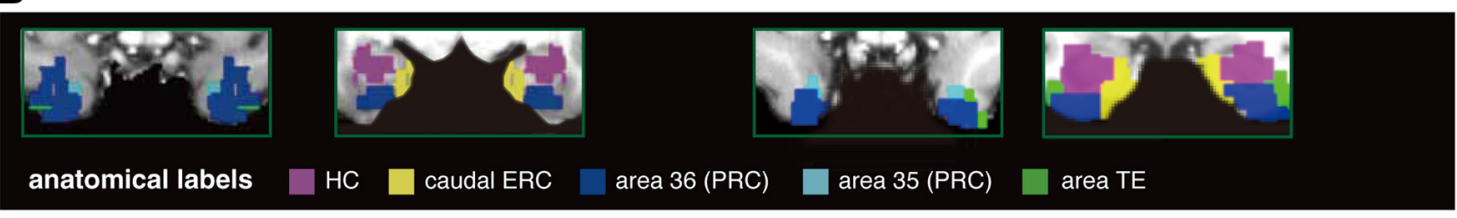

Figure 2. Prediction maps showing the accuracy of the classification of "later Hit" and "later Miss" trials during the single-probe recognition task for each monkey $(\boldsymbol{A})$ and anatomical partitioning by Paxinos et al. (2008) (B) superimposed on coronal sections. HC, Hippocampus.

A
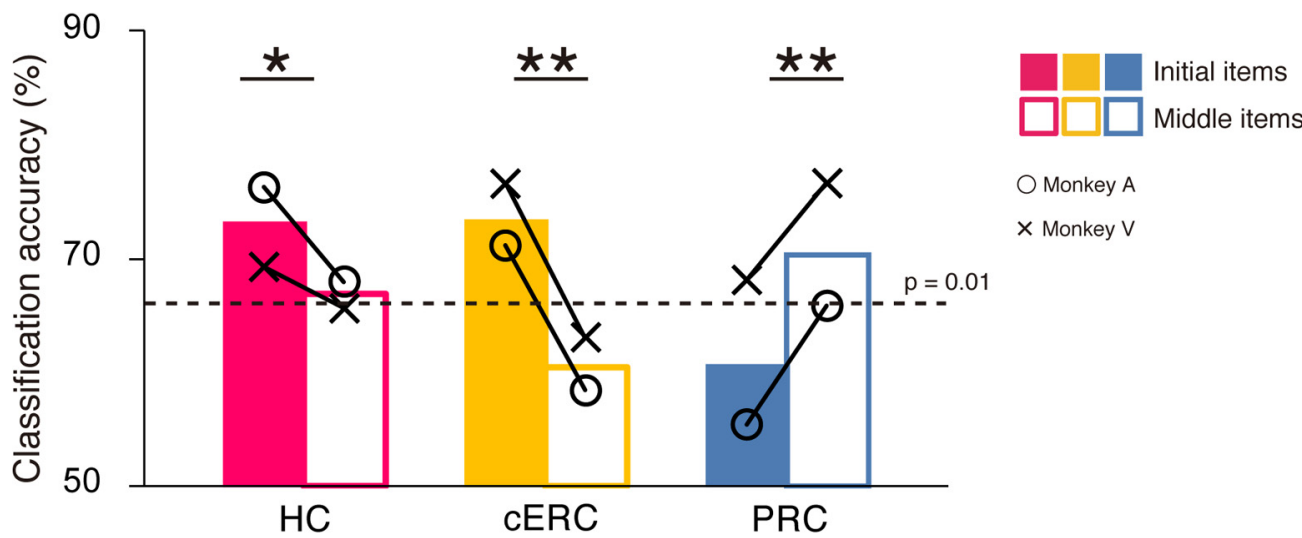

Monkey A

$\times$ Monkey $\mathrm{V}$

B

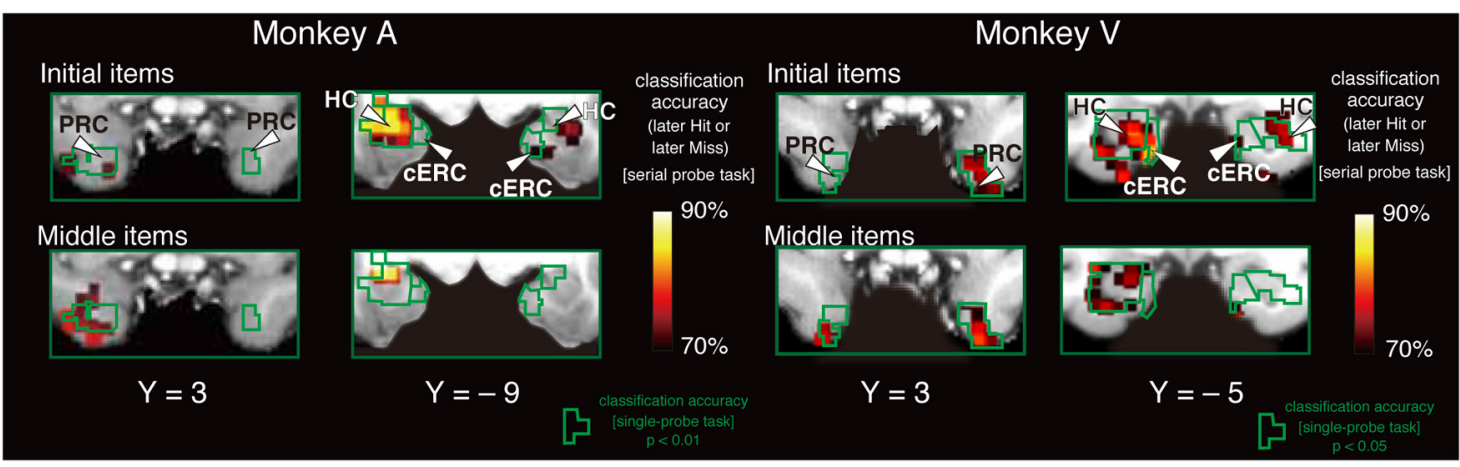

Figure 3. Differential predictability of subsequent memory performance according to multivoxel classification. $A$, Classification accuracy of the initial (filled bars) and middle (open bars) items within a picture list for each monkey in the serial probe recognition task. The decoding accuracy of the hippocampus (HC) and the cERC was higher for initial items than for middle items, whereas the accuracy of the PRC was higher for middle items than for initial items. ${ }^{*} p<0.05$. ${ }^{* *} p<0.01$. Dashed line indicates significant prediction accuracy with $p=0.01$ (binominal test, population analysis). $\bigcirc$ represents Monkey A, and $\times$ represents Monkey V. $\boldsymbol{B}$, Prediction maps showing the accuracy of the classifications during the serial probe recognition task for each monkey. Regions enclosed in green represent significantly high predictability in the single-probe recognition task.

and the cERC $(p<0.05$; Table 2$)$. Time courses of BOLD signal for later Hit and later Miss trials confirmed that these two areas show responses predictive of subsequent memory performance (Fig. $4 B$ ). The activation patterns around the peak in the PRC and cERC detected by the univariate analysis (Table
2) also adequately predicted subsequent memory performance by the multivariate decoding analysis (PRC, Monkey A: 70\%, Monkey V: $66 \%, p<0.01$ for both; cERC, Monkey A: 66\%, Monkey V: 63\%, $p<0.05$ for both; Fig. $4 C$ ). However, the univariate analysis was not sufficiently sensitive to identify the 


\section{A}

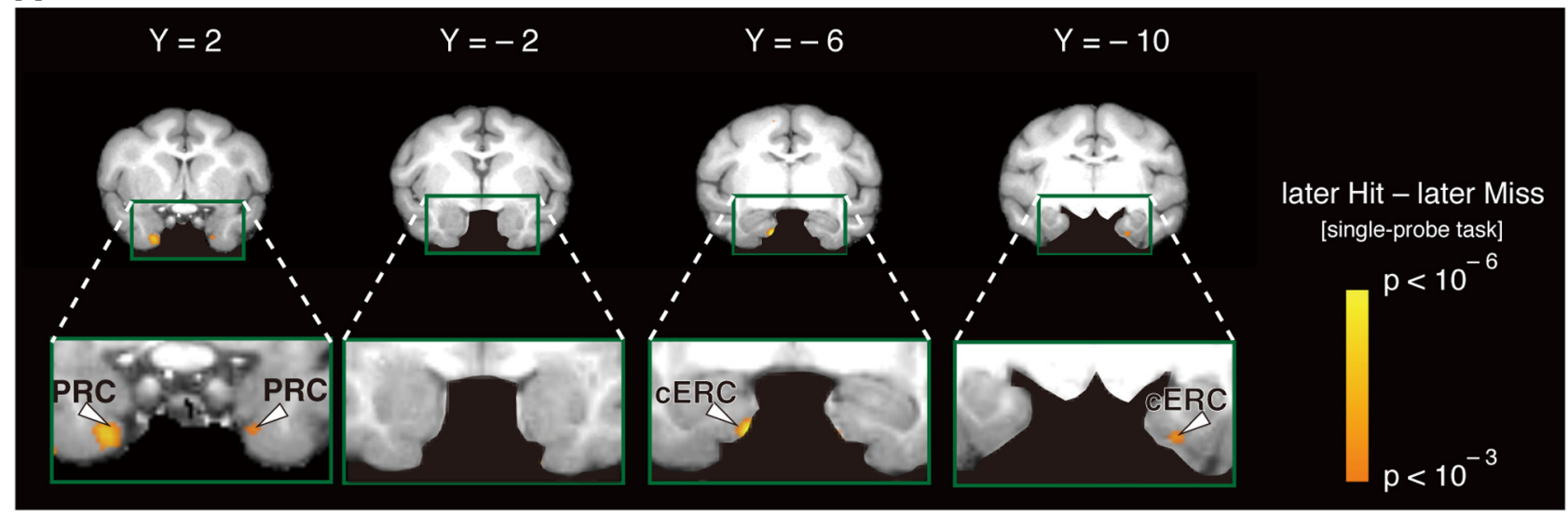

B

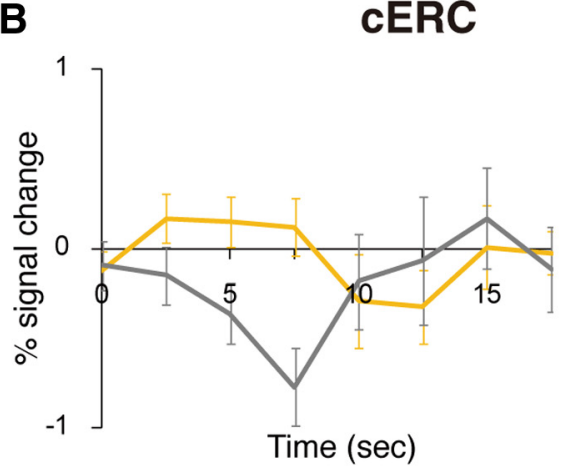

later Hit

C

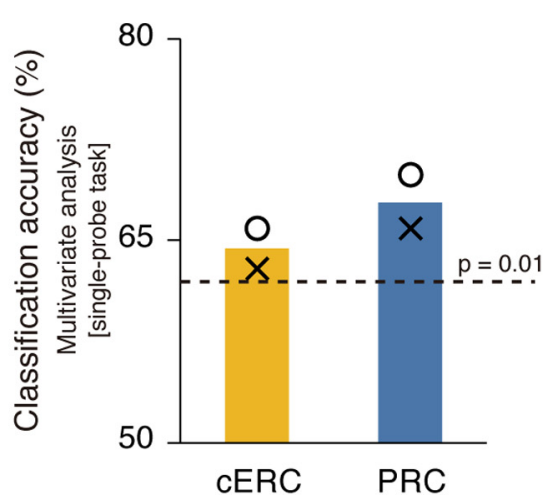

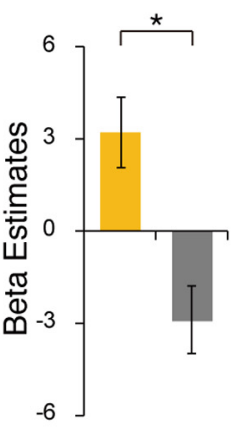

later Miss

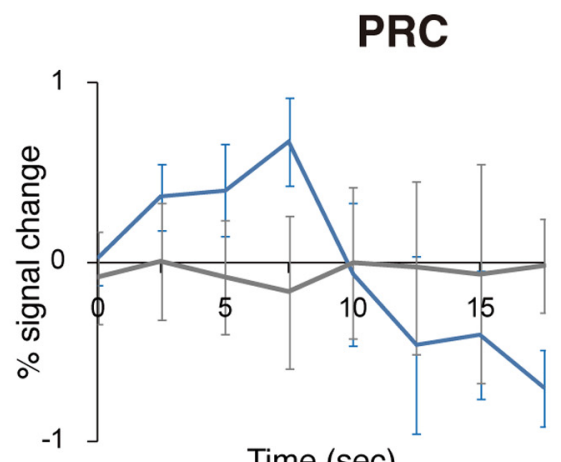

Time (sec)

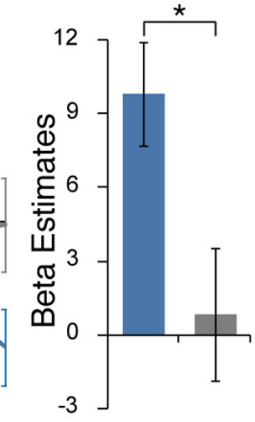

later Miss
D

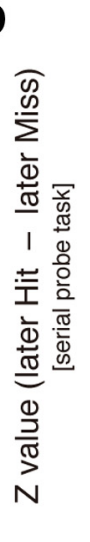

later Hit

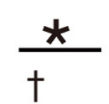

t*

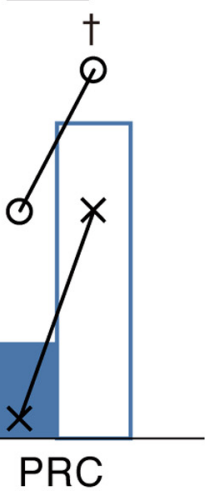

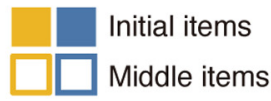

Monkey A

$\times$ Monkey $\mathrm{V}$

Figure 4. Differential subsequent memory effects between macaque MTL regions identified by univariate analysis. $\boldsymbol{A}$, Activation maps (later Hit $>$ later Miss) for the single-probe recognition task superimposed on coronal sections $(t>3.1, p<0.001)$. B , Percentage signal change is graphed for later Hit and later Miss trials across $17.5 \mathrm{~s}$ (7 time points) after trial onset in the cERC and PRC. Bar graphs represent the parameter estimates. Error bars indicate SEM (across sessions). C, Classification accuracy in the activated regions in a $2 \mathrm{~mm}$ radius sphere around the peak detected by univariate analysis in the single-probe recognition task (Table 1). Dashed line indicates significant prediction accuracy with $p=0.01$ (binominal test, population analysis). $\bigcirc$ represents Monkey $A$, and $\times$ represents Monkey V. D, Activation values for the "later Hit" trials compared with those in the "later Miss" trials for initial items and middle items in the serial probe recognition task in the cERC (yellow) and the PRC (blue). The activation value of the cERC was higher for initial items than for middle items, whereas the value of the PRC was higher for middle items than for initial items. $\uparrow p<$ 0.05 (FWE-corrected, SVC within each area). ${ }^{*} p<0.05 .{ }^{* *} p<0.01$. $\bigcirc$ represents Monkey A, and $\times$ represents Monkey V.

bilateral hippocampi as loci that predicted subsequent memory performance.

\section{Functional dissociation between PRC and cERC during} memory encoding ascertained by univariate analysis Finally, we examined whether the functional dissociation between the PRC and cERC in the serial probe recognition task, whereby the prediction of subsequent memory performance was differentially affected by the position of the cue item in the list, was also detected by univariate analysis (Fig. 4D). A subsequent memory effect on the brain activity was significantly observed in the cERC during the encoding of initial items $(p=0.03$, FWEcorrected, small volume correction [SVC]), but not during the encoding of middle items $(p=0.35)$. Significant subsequent memory-related activity was observed in the PRC during the encoding of middle items $(p=0.03)$, but not during the encoding of initial items $(p>0.5)$. Two-way ANOVA (two positions [initial, middle] $\times$ two areas $[\mathrm{cERC}, \mathrm{PRC}])$ identified a significant interaction between position and area $\left(F_{(2,2)}=4.06 \times 10^{4}, p=\right.$ $0.003)$, although neither position $\left(F_{(1,1)}=7.17, p=0.22\right)$ nor 
area $\left(F_{(1,2)}=0.02, p>0.5\right)$ showed a significant main effect. The cERC and PRC were then dissociated to determine their contribution to encoding items in different positions in the cue list. Tests for simple main effects revealed that the activation value of the $\operatorname{cERC}\left(F_{(1,2)}=39.0\right.$, $p=0.02)$ was significantly higher for initial items than for middle items, whereas the value of the PRC was significantly higher for middle items than for initial items $\left(F_{(1,2)}=134, p=0.007\right)$. These results reproduced the observations from the multivariate decoding analysis (Fig. $3 A)$.

To ensure that this functional differentiation between PRC and cERC could not be simply explained by a gross difference in memory recognition accuracy (Fig. $1 B)$, or memory strength, we also estimated the correlation between the behavioral performance on each day and brain activity in the two regions (the initial and middle items were analyzed separately) (Fig. 5). The fMRI signal in the cERC showed a significant positive correlation with the memory recognition accuracy across the sessions for the initial items ( $r=0.45, p=0.02)$, but not for the middle items $(r=-0.08, p>0.5)$. In contrast, the fMRI signal in the PRC showed a significant positive correlation with the memory recognition accuracy across sessions for the middle items $(r=0.39, p=0.04)$, but not for the initial items $(r=-0.01, p>0.5)$. In summary, the activity of the cERC or PRC was predicted by memory recognition accuracy only when monkeys encoded the initial or middle items, respectively. These results corroborate the existence of two qualitatively distinct encoding processes in the MTL (Fig. 6).

\section{Discussion}

The present study is the first to identify the locus of memory formation in macaque monkeys using fMRI. Multivoxel pattern analysis and conventional univariate analysis identified encoding success regions that showed a subsequent memory effect in the hippocampus, PRC, and cERC. Moreover, these areas were functionally differentiated and responsible for encoding items in different positions.

Our results indicated that the hippocampus was responsible for encoding the initial item in the list, which is related to the primacy effect. The result is consistent with observations in studies of humans that suggest that damage to the bilateral hippocampi specifically impairs primacy effect (Baddeley and Warrington, 1970). Electrophysiological recordings in the macaque monkeys have shown that the hippocampus predicts subsequent recognition memory performance (Jutras et al., 2009) and especially plays a role in the encoding of contextual information (Suzuki and Eichenbaum, 2000; Brown and Aggleton, 2001), including spatial location (Rolls, 1999) and temporal order (Naya and Suzuki, 2011). Lesion studies in rats also support these recollectionlike roles of the hippocampus (Fortin et al., 2004; Crystal et al., 2013). In psychological models of the serial position effect, the primacy effect for the initial item and the decline of performance
Initial items

Middle items
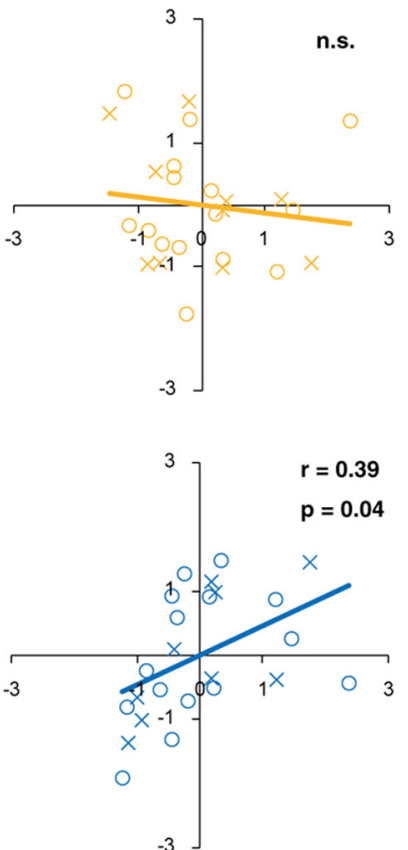

normalized memory recognition accuracy

[serial probe task]

Figure 5. Intersession correlation between memory accuracy and subsequent memory effect. Intersession brain activity in the CERC for initial item retrieval and in the PRC for middle item retrieval was positively correlated with performance. The $x$-axis indicates the memory recognition accuracy ( $z$-transformed), and the $y$-axis indicates the encoding success activity (z-transformed). represents Monkey A, and $\times$ represents Monkey V.

for the middle items are thought to result from association of each list item with some representation of the start-of-list context, with the strength of association decreasing with list position (Page and Norris, 1998; Farrell and Lewandowsky, 2002). Therefore, contextual processing is considered to have a greater effect on the encoding of the initial item than the middle items. Indeed, involvement of the human hippocampus in contextual and primacy effect-related processing (Baddeley and Warrington, 1970; Rugg and Yonelinas, 2003) supports this idea. The encoding success regions that were localized within the hippocampus in this monkey fMRI experiment may reflect contextual processing that effectively works during encoding of the initial item, which is the most distinctive item in a list.

We localized an encoding success region within the cERC in monkeys. The cERC is known to strongly project to the hippocampus and to receive major cortical input from parahippocampal and retrosplenial cortices rather than from the PRC (Amaral et al., 1987). The observation that the cERC, along with the hippocampus, was functionally differentiated from the PRC during memory encoding is consistent with the literature on brain anatomy of macaque monkeys (Amaral et al., 1987).

Unlike the hippocampus, involvement of the cERC in memory encoding has rarely been reported in humans, likely because the precise demarcation of the entorhinal cortex located on the human parahippocampal gyrus from other cortices is difficult because of the scarcity of MRI-based boundary delineations in the gyrus (for anatomy and nomenclatures of these regions, see Materials and Methods). Recent human fMRI studies have shown that the middle parahippocampal gyrus is responsible for contextual or scene processing, whereas the anterior parahippocam- 
A

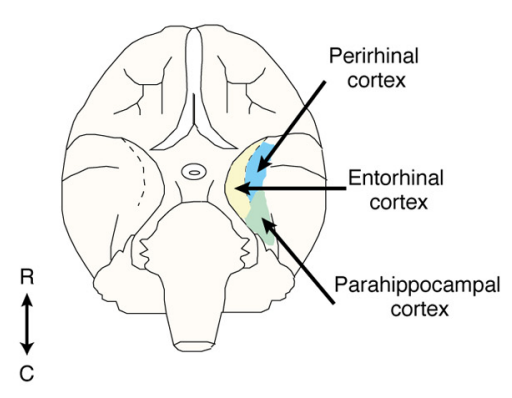

B

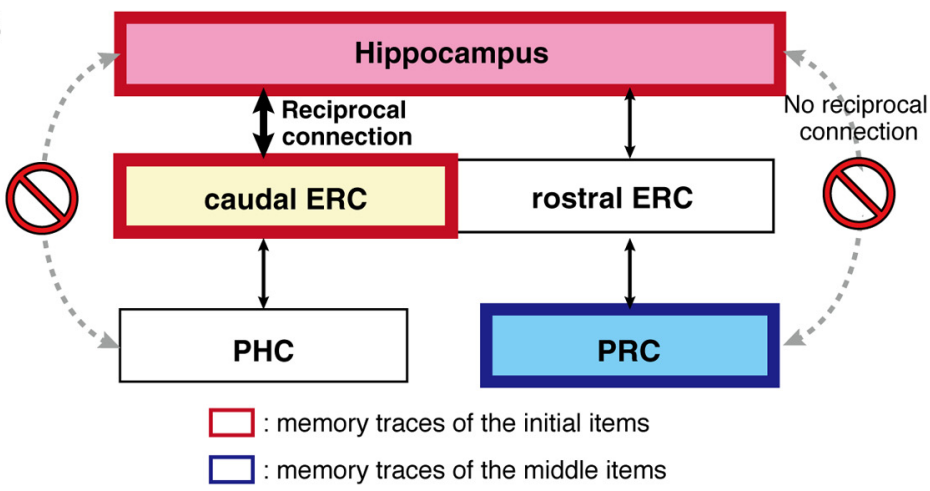

Figure 6. New insights into the primate memory-encoding system obtained from the present study. $\boldsymbol{A}$, The distribution of regions within the MTL (blue represents PRC; yellow, ERC; green, PHC) in monkey brain. Modified from Mayford et al. (1997). R, rostral; $\boldsymbol{C}$, caudal. $\boldsymbol{B}$, Schemata of the primate memory-encoding processes proposed according to results of the present monkey fMRI study. This view of the primate memory-encoding system suggests that memory traces related to initial items are formed in the hippocampus and the caudal ERC, whereas memory traces related to middle items are formed in the PRC. This is consistent with the literature on anatomy of monkeys, which has reported that the hippocampus has major reciprocal direct connections with the caudal ERC but not with the PRC.

pal gyrus is not (Staresina et al., 2011; Hannula et al., 2013). The present monkey study suggests a possibility that the middle part of parahippocampal gyrus in humans, which is repeatedly referred to as the "PHC," corresponds to the macaque cERC. In monkeys, the entorhinal cortex distributes at a higher level than the $\mathrm{PHC}$ in the hierarchical processing network that is shaped by anatomical connectivity patterns (Felleman and Van Essen, 1991). Therefore, the process of encoding recollection-based memory may occur in an area anatomically closer to the hippocampus and hierarchically higher than previously believed (Fig. 6). This would redefine the memory encoding network in the primate MTL.

In the present monkey study, no significant activation peaks $(p>0.5)$ related to subsequent memory effect were identified within the PHC (area TH and TF) in the group analysis map of the two monkeys in the univariate analysis. Classification accuracy for memory retrieval performance predicted by activity patterns within the PHC was different between subjects: for Monkey A, memory retrieval performance was predicted by voxel patterns within the PHC (accuracy peaks; L: $[x, y, z]=[-13,-16,-10]$, accuracy $=82.1 \%, p<0.001 ; \mathrm{R}:[x, y, z]=[13,-13,-13]$, accuracy $=77.8 \%, p<0.001)$, but this was not the case for Monkey V (L, R: accuracy in all the voxels in the PHC $<55.4 \%$, $p>0.24)$. Therefore, the PHC in monkeys does not predict subsequent memory performance better than the cERC where robust memory traces were identified in all the analyses. The intersubject difference in classification accuracy in the PHC may be the result of the different levels of memory performance in the two monkeys (Fig. 1B).

We also localized an encoding success region within area 36 of the PRC. The PRC was responsible for encoding items presented in the middle of the cue list. For these middle items, the monkeys may have adopted encoding strategies based on familiarity rather than recollection because they were less likely to use distinctiveness within a picture list, or contextual information, to encode middle items than they were to encode initial items. Electrophysiological studies in monkeys have shown that area 36 contains neurons that represent visual long-term memory (Miyashita, 1988) and that the activity of these neurons was different for familiar and new stimuli (Li et al., 1993; Xiang and Brown, 1998). The encoding success regions localized within the PRC in this monkey fMRI study may reflect neuronal correlates such as these.

All items in the cue picture list might be subject to both contextual encoding and familiarity-based encoding. However, our results show differential activity patterns (Figs. 3 and Fig. 4D) and differential correlations with behavior (Fig. 5) for the encoding of initial and middle items. These results suggest the existence of two qualitatively distinct encoding processes, and biases in the contribution of such processes, for initial and middle items. According to the psychological models (Page and Norris, 1998; Farrell and Lewandowsky, 2002), contextual encoding processes are considered to work better for initial items than middle items, even if familiarity signals were produced in parallel. By contrast, familiarity-based encoding processes without contextual information may work relatively better for middle items than for initial items. Retrieval of the last items on the list is related to the recency effect and is considered to reflect working memory process rather than long-term memory process. Actually, the activation related to the encoding success effect during encoding of the last item was not significant in either the PRC $(p=0.81)$ or the cERC $(p=0.13)$. These results support the idea that the memory encoding processes for the last item are different from those for the initial or middle items. Other explanations for the observed differential activation patterns may be possible. For instance, differences in the correct response rate between monkeys, or differences in the extent to which the monkey intensively encoded the item, might explain the difference; however, these explanations are not consistent with the fact that the cERC activity during encoding was significantly positive for the initial items but not for last items, despite a similar correct response rate.

In the present study, we have interpreted results from monkeys by comparison to those from humans. We compared time courses during encoding obtained from monkeys (Fig. 4B) to those from humans (Staresina and Davachi, 2006) and found that the time courses for later Hit and later Miss trials in the PRC and cERC were more similar to those in the human MTL than to those in the human prefrontal cortex (inferior frontal gyrus). This observation also suggested the interspecies similarity of encoding success effect-related activity in the MTL.

In this study, we precisely localized and characterized the MTL sites responsible for memory encoding in monkeys and, consequently, propose a new interspecies correspondence in the MTL between humans and monkeys. Our findings using monkey fMRI will advance the understanding of primate memory systems by bridging the gap between imaging studies in humans and electrophysiological studies in monkeys. 


\section{References}

Adachi Y, Osada T, Sporns O, Watanabe T, Matsui T, Miyamoto K, Miyashita Y (2012) Functional connectivity between anatomically unconnected areas is shaped by collective network-level effects in the macaque cortex. Cereb Cortex 22:1586-1592. CrossRef Medline

Amaral DG, Insausti R, Cowan WM (1987) The entorhinal cortex of the monkey: I. Cytoarchitectonic organization. J Comp Neurol 264:326-355. CrossRef Medline

Augustinack JC, Huber KE, Stevens AA, Roy M, Frosch MP, van der Kouwe AJ, Wald LL, Van Leemput K, McKee AC, Fischl B (2013) Predicting the location of human perirhinal cortex, Brodmann's area 35, from MRI. Neuroimage 64:32-42. CrossRef Medline

Baddeley AD, Warrington EK (1970) Amnesia and the distinction between long- and short-term memory. J Verb Learn Verb Behav 9:176-189. CrossRef

Blatt GJ, Pandya DN, Rosene DL (2003) Parcellation of cortical afferents to three distinct sectors in the parahippocampal gyrus of the rhesus monkey: an anatomical and neurophysiological study. J Comp Neurol 466:161179. CrossRef Medline

Brown MW, Aggleton JP (2001) Recognition memory: what are the roles of the perirhinal cortex and hippocampus? Nat Rev Neurosci 2:51-61. CrossRef Medline

Burwell RD (2000) The parahippocampal region: corticocortical connectivity. Ann N Y Acad Sci 911:25-42. CrossRef Medline

Crystal JD, Alford WT, Zhou W, Hohmann AG (2013) Source memory in the rat. Curr Biol 23:387-391. CrossRef Medline

Davachi L (2006) Item, context and relational episodic encoding in humans. Curr Opin Neurobiol 16:693-700. CrossRef Medline

Ding SL, Van Hoesen GW (2010) Borders, extent, and topography of human perirhinal cortex as revealed using multiple modern neuroanatomical and pathological markers. Hum Brain Mapp 31:1359-1379. CrossRef Medline

Durand JB, Nelissen K, Joly O, Wardak C, Todd JT, Norman JF, Janssen P, Vanduffel W, Orban GA (2007) Anterior regions of monkey parietal cortex process visual 3D shape. Neuron 55:493-505. CrossRef Medline

Farrell S, Lewandowsky S (2002) An endogenous distributed model of ordering in serial recall. Psychon Bull Rev 9:59-79. CrossRef Medline

Felleman DJ, Van Essen DC (1991) Distributed hierarchical processing in the primate cerebral cortex. Cereb Cortex 1:1-47. CrossRef Medline

Ford KA, Gati JS, Menon RS, Everling S (2009) BOLD fMRI activation for anti-saccades in nonhuman primates. Neuroimage 45:470-476. CrossRef Medline

Fortin NJ, Wright SP, Eichenbaum H (2004) Recollection-like memory retrieval in rats is dependent on the hippocampus. Nature 431:188-191. CrossRef Medline

Genovese CR, Lazar NA, Nichols T (2002) Thresholding of statistical maps in functional neuroimaging using the false discovery rate. Neuroimage 15:870-878. CrossRef Medline

Hannula DE, Libby LA, Yonelinas AP, Ranganath C (2013) Medial temporal lobe contributions to cued retrieval of items and contexts. Neuropsychologia 15:2322-2332. CrossRef Medline

Hassabis D, Chu C, Rees G, Weiskopf N, Molyneux PD, Maguire EA (2009) Decoding neuronal ensembles in the human hippocampus. Curr Biol 19:546-554. CrossRef Medline

Haynes JD, Rees G (2005) Predicting the orientation of invisible stimuli from activity in human primary visual cortex. Nat Neurosci 8:686-691. CrossRef Medline

Insausti R, Juottonen K, Soininen H, Insausti AM, Partanen K, Vainio P, Laakso MP, Pitkänen A (1998) MR volumetric analysis of the human entorhinal, perirhinal, and temporopolar cortices. AJNR Am J Neuroradiol 19:659-671. Medline

Johnson JD, McDuff SG, Rugg MD, Norman KA (2009) Recollection, familiarity, and cortical reinstatement: a multivoxel pattern analysis. Neuron 63:697-708. CrossRef Medline

Jutras MJ, Fries P, Buffalo EA (2009) Gamma-band synchronization in the macaque hippocampus and memory formation. J Neurosci 29:1252112531. CrossRef Medline

Kagan I, Iyer A, Lindner A, Andersen RA (2010) Space representation for eye movements is more contralateral in monkeys than in humans. Proc Natl Acad Sci U S A 107:7933-7938. CrossRef Medline

Kamitani Y, Tong F (2005) Decoding the visual and subjective contents of the human brain. Nat Neurosci 8:679-685. CrossRef Medline
Kay KN, Naselaris T, Prenger RJ, Gallant JL (2008) Identifying natural images from human brain activity. Nature 452:352-355. CrossRef Medline

Kondo H, Saleem KS, Price JL (2003) Differential connections of the temporal pole with the orbital and medial prefrontal networks in macaque monkeys. J Comp Neurol 465:499-523. CrossRef Medline

Kondo H, Saleem KS, Price JL (2005) Differential connections of the perirhinal and parahippocampal cortex with the orbital and medial prefrontal networks in macaque monkeys. J Comp Neurol 493:479-509. CrossRef Medline

Koyama M, Hasegawa I, Osada T, Adachi Y, Nakahara K, Miyashita Y (2004) Functional magnetic resonance imaging of macaque monkeys performing visually guided saccade tasks: comparison of cortical eye fields with humans. Neuron 41:795-807. CrossRef Medline

Kriegeskorte N, Goebel R, Bandettini P (2006) Information-based functional brain mapping. Proc Natl Acad Sci U S A 103:3863-3868. CrossRef Medline

Li L, Miller EK, Desimone R (1993) The representation of stimulus familiarity in anterior inferior temporal cortex. J Neurophysiol 69:1918-1929. Medline

Logothetis NK, Guggenberger H, Peled S, Pauls J (1999) Functional imaging of the monkey brain. Nat Neurosci 2:555-562. CrossRef Medline

Maier A, Wilke M, Aura C, Zhu C, Ye FQ, Leopold DA (2008) Divergence of fMRI and neural signals in V1 during perceptual suppression in the awake monkey. Nat Neurosci 11:1193-1200. CrossRef Medline

Matsui T, Koyano KW, Tamura K, Osada T, Adachi Y, Miyamoto K, Chikazoe J, Kamigaki T, Miyashita Y (2012) FMRI activity in the macaque cerebellum evoked by intracortical microstimulation of the primary somatosensory cortex: evidence for polysynaptic propagation. PLoS One 7:e47515. CrossRef Medline

Mayford M, Mansuy IM, Muller RU, Kandel ER (1997) Memory and behavior: a second generation of genetically modified mice. Curr Biol 7:R580 R589. CrossRef Medline

Meunier M, Hadfield W, Bachevalier J, Murray EA (1996) Effects of rhinal cortex lesions combined with hippocampectomy on visual recognition memory in rhesus monkeys. J Neurophysiol 75:1190-1205. Medline

Mitchell TM, Shinkareva SV, Carlson A, Chang KM, Malave VL, Mason RA, Just MA (2008) Predicting human brain activity associated with the meanings of nouns. Science 320:1191-1195. CrossRef Medline

Miyamoto K, Osada T, Adachi Y, Matsui T, Kimura HM, Miyashita Y (2013) Functional differentiation of memory retrieval network in macaque posterior parietal cortex. Neuron 77:787-799. CrossRef Medline

Miyashita Y (1988) Neuronal correlate of visual associative long-term memory in the primate temporal cortex. Nature 335:817-820. CrossRef Medline

Miyashita Y (2004) Cognitive memory: cellular and network machineries and their top-down control. Science 306:435-440. CrossRef Medline

Murray EA, Mishkin M (1986) Visual recognition in monkeys following rhinal cortical ablations combined with either amygdalectomy or hippocampectomy. J Neurosci 6:1991-2003. Medline

Nakahara K, Hayashi T, Konishi S, Miyashita Y (2002) Functional MRI of macaque monkeys performing a cognitive set-shifting task. Science 295: 1532-1536. CrossRef Medline

Naya Y, Suzuki WA (2011) Integrating what and when across the primate medial temporal lobe. Science 333:773-776. CrossRef Medline

Page MP, Norris D (1998) The primacy model: a new model of immediate serial recall. Psychol Rev 105:761-781. CrossRef Medline

Paxinos G, Huang XF, Petrides M, Toga AW (2008) The rhesus monkey brain in stereotactic coordinates. London: Elsevier Academic.

Pinsk MA, DeSimone K, Moore T, Gross CG, Kastner S (2005) Representations of faces and body parts in macaque temporal cortex: a functional MRI study. Proc Natl Acad Sci U S A 102:6996-7001. CrossRef Medline

Ranganath C, Yonelinas AP, Cohen MX, Dy CJ, Tom SM, D'Esposito M (2004) Dissociable correlates of recollection and familiarity within the medial temporal lobes. Neuropsychologia 42:2-13. CrossRef Medline

Rolls ET (1999) Spatial view cells and the representation of place in the primate hippocampus. Hippocampus 9:467-480. CrossRef Medline

Rugg MD, Yonelinas AP (2003) Human recognition memory: a cognitive neuroscience perspective. Trends Cogn Sci 7:313-319. CrossRef Medline

Saleem KS, Kondo H, Price JL (2008) Complementary circuits connecting the orbital and medial prefrontal networks with the temporal, insular, and opercular cortex in the macaque monkey. J Comp Neurol 506:659-693. CrossRef Medline 
Squire LR, Stark CE, Clark RE (2004) The medial temporal lobe. Annu Rev Neurosci 27:279-306. CrossRef Medline

Staresina BP, Davachi L (2006) Differential encoding mechanisms for subsequent associative recognition and free recall. J Neurosci 26:9162-9172. CrossRef Medline

Staresina BP, Duncan KD, Davachi L (2011) Perirhinal and parahippocampal cortices differentially contribute to later recollection of object- and scene-related event details. J Neurosci 31:8739-8747. CrossRef Medline

Strange BA, Otten LJ, Josephs O, Rugg MD, Dolan RJ (2002) Dissociable human perirhinal, hippocampal, and parahippocampal roles during verbal encoding. J Neurosci 22:523-528. Medline

Suzuki WA, Amaral DG (1994a) Perirhinal and parahippocampal cortices of the macaque monkey: cortical afferents. J Comp Neurol 350:497-533. CrossRef Medline

Suzuki WA, Amaral DG (1994b) Topographic organization of the reciprocal connections between the monkey entorhinal cortex and the perirhinal and parahippocampal cortices. J Neurosci 14:1856-1877. Medline

Suzuki WA, Amaral DG (2003a) Where are the perirhinal and parahippocampal cortices? A historical overview of the nomenclature and boundaries applied to the primate medial temporal lobe. Neuroscience 120:893-906. CrossRef Medline

Suzuki WA, Amaral DG (2003b) Perirhinal and parahippocampal cortices of the macaque monkey: cytoarchitectonic and chemoarchitectonic organization. J Comp Neurol 463:67-91. CrossRef Medline

Suzuki WA, Eichenbaum H (2000) The neurophysiology of memory. Ann N Y Acad Sci 911:175-191. CrossRef Medline

Tsao DY, Freiwald WA, Knutsen TA, Mandeville JB, Tootell RB (2003)
Faces and objects in macaque cerebral cortex. Nat Neurosci 6:989-995. CrossRef Medline

Van Hoesen GW, Augustinack JC, Dierking J, Redman SJ, Thangavel R (2000) The parahippocampal gyrus in Alzheimer's disease: clinical and preclinical neuroanatomical correlates. Ann N Y Acad Sci 911:254-274. CrossRef Medline

Wagner AD, Schacter DL, Rotte M, Koutstaal W, Maril A, Dale AM, Rosen BR, Buckner RL (1998) Building memories: remembering and forgetting of verbal experiences as predicted by brain activity. Science 281: 1188-1191. CrossRef Medline

Wais PE (2008) FMRI signals associated with memory strength in the medial temporal lobes: a meta-analysis. Neuropsychologia 46:3185-3196. CrossRef Medline

Wang Z, Chen LM, Négyessy L, Friedman RM, Mishra A, Gore JC, Roe AW (2013) The relationship of anatomical and functional connectivity to resting-state connectivity in primate somatosensory cortex. Neuron 78: 1116-1126. CrossRef Medline

Watanabe T, Hirose S, Wada H, Katsura M, Chikazoe J, Jimura K, Imai Y, Machida T, Shirouzu I, Miyashita Y, Konishi S (2011) Prediction of subsequent recognition performance using brain activity in the medial temporal lobe. Neuroimage 54:3085-3092. CrossRef Medline

Wright AA, Santiago HC, Sands SF, Kendrick DF, Cook RG (1985) Memory processing of serial lists by pigeons, monkeys, and people. Science 229: 287-289. CrossRef Medline

Xiang JZ, Brown MW (1998) Differential neuronal encoding of novelty, familiarity and recency in regions of the anterior temporal lobe. Neuropharmacology 37:657-676. CrossRef Medline 